\title{
Effects of Cold Atmospheric Plasma on the Expression of Chemokines, Growth Factors, TNF Superfamily Members, Interleukins, and Cytokines in Human Osteosarcoma Cells
}

\author{
LYUBOMIR HARALAMBIEV ${ }^{1,2}$, LASSE WIEN $^{1,3}$, NADINE GELBRICH $^{3}$, \\ AXEL KRAMER $^{4}$, ALEXANDER MUSTEA ${ }^{5}$, MARTIN BURCHARDT $^{3}$, \\ AXEL EKKERNKAMP ${ }^{1,2}$, MATTHIAS B. STOPE $^{3}$ and DENIS GÜMBEL ${ }^{1,2}$ \\ ${ }^{I}$ Department of Trauma, Reconstructive Surgery and Rehabilitation Medicine, \\ University Medicine Greifswald, Greifswald, Germany; \\ ${ }^{2}$ Department of Trauma and Orthopaedic Surgery, \\ $B G$ Klinikum Unfallkrankenhaus Berlin gGmbH, Berlin, Germany; \\ ${ }^{3}$ Department of Urology, University Medicine Greifswald, Greifswald, Germany; \\ ${ }^{4}$ Institute of Hygiene and Environmental Medicine, University Medicine Greifswald, Greifswald, Germany; \\ ${ }^{5}$ Department of Gynecology and Obstetrics, University Medicine Greifswald, Greifswald, Germany
}

\begin{abstract}
Background/Aim: Therapeutic options for osteosarcoma (OS) are still limited. Cold atmospheric plasma (CAP) leads to inhibition of tumor growth and metastasis, but underlying mechanisms are not fully understood. The aim of this study was to investigate CAPinduced changes in cytokine expression in OS cells. Materials and Methods: OS cell lines (U2-OS, MNNG/HOS) were treated with CAP and administered to an RT2 Profiler PCR Array (Qiagen, Hilden, Germany) detecting 84 chemokines, growth factors, TNF superfamily members, interleukins, and cytokines. Results: The analyses showed that 15 factors (C5, CCL5, CNTF, CSF1, CSF3, CXCL1, IL$1 A, I L-1 B, I L-18, I L-22, I L 23 A, M S T N, N O D A L, T G F \beta 2$, THPO) were induced, but only one factor (VEGFA) was suppressed after CAP treatment. Conclusion: No extensive systemic cell response with presumably far-reaching consequences for neighboring cells was detectable after CAP treatment. Since the antitumoral effect of CAP on OS cells has already been demonstrated, intraoperative treatment with CAP represents a promising and systemic safe option for the therapy of $O S$.
\end{abstract}

Correspondence to: Lyubomir Haralambiev, University Medicine Greifswald, Department of Trauma, Reconstructive Surgery and Rehabilitation Medicine, Ferdinand Sauerbruch Straße, 17475 Greifswald, Germany. Tel: +49 38348622541, Fax: +49 3834866013, e-mail: lyubomir.haralambiev@uni-greifswald.de

Key Words: Cytokine, chemokine, cold atmospheric plasma, osteosarcoma.
Osteosarcoma (OS) is the most common bone cancer in humans and at initial diagnosis, metastases are present in about $20 \%$ of all cases. Standard therapy includes radical surgical resection and chemotherapy, but due to strong toxic effects, new treatment options are urgently needed (1). Currently, there is a growing discussion about expanding the oncological therapy spectrum and treat with cold atmospheric plasma (CAP) $(2,3)$. CAP represents a highly reactive ionized gas containing radicals, ions, photons, and electromagnetic rays. Its biological effects are primarily mediated by reactive oxygen and nitrogen species (RONS) such as singlet oxygen, superoxide, ozone, hydroxyl radicals, nitrogen radicals, nitric oxide, nitrogen dioxide, peroxynitrite, and hydrogen peroxide (4). Due to its low, almost body-warm temperature, CAP is ideally suited for medical applications and has been used for many years in the treatment of skin diseases and chronic wounds (5). In the context of oncological therapy, the in vitro effect of CAP treatment has already been demonstrated for numerous tumor entities including melanoma (6), prostate cancer (7), glioblastoma (8), pancreatic cancer (9), head and neck cancer (10), colon cancer (11), lung cancer (12), leukemia (13), and gastric cancer (14). Initial preliminary in vivo studies have shown the antitumoral effect of CAP also for pancreatic cancer (14), melanoma (15), ovarian cancer (16), breast cancer (17), and colon cancer (18). The molecular and cellular mechanisms leading to an inactivation of malignant cells, however, are still poorly investigated and largely unclear.

In OS cells, inhibition of cell growth after CAP treatment has been demonstrated. This was due to the activation of redox signalling cascades, which affected mitochondria's 
Table I. Human Cytokines \& Chemokines RT2 Profiler PCR Array (Qiagen). Abbreviation (symbol) and description of all 84 cytokines analyzed by the PCR array in this study. The column "detectable" indicates whether the factor was detected $(+)$ or not detected (-).

\begin{tabular}{|c|c|c|c|}
\hline Number & Symbol & Description & Detectable \\
\hline & \multicolumn{3}{|c|}{ Chemokines } \\
\hline 1 & C5 & Complement component 5 & + \\
\hline 2 & CCL1 & (C-C motif) ligand 1 & - \\
\hline 3 & CCL2 & (C-C motif) ligand 2 & - \\
\hline 4 & CCL3 & (C-C motif) ligand 3 & - \\
\hline 5 & CCL5 & (C-C motif) ligand 5 & + \\
\hline 6 & CCL7 7 & (C-C motif) ligand 7 & - \\
\hline 7 & CCL8 & (C-C motif) ligand 8 & - \\
\hline 8 & CCL11 & (C-C motif) ligand 11 & - \\
\hline 9 & CCL13 & (C-C motif) ligand 13 & - \\
\hline 10 & CCL17 & (C-C motif) ligand 17 & - \\
\hline 11 & CCL18 & (C-C motif) ligand 18 & - \\
\hline 12 & CCL19 & (C-C motif) ligand 19 & - \\
\hline 13 & CCL20 & (C-C motif) ligand 20 & - \\
\hline 14 & CCL21 & (C-C motif) ligand 21 & - \\
\hline 15 & CCL22 & (C-C motif) ligand 22 & - \\
\hline 16 & CCL24 & (C-C motif) ligand 24 & - \\
\hline 17 & CXCL1 & Chemokine (C-X-C motif) ligand 1 & + \\
\hline 18 & CXCL2 & Chemokine (C-X-C motif) ligand 2 & - \\
\hline 19 & CXCL5 & Chemokine (C-X-C motif) ligand 5 & - \\
\hline 20 & CXCL9 & Chemokine (C-X-C motif) ligand 9 & - \\
\hline 21 & CXCL10 & Chemokine (C-X-C motif) ligand 10 & - \\
\hline 22 & CXCL11 & Chemokine (C-X-C motif) ligand 11 & - \\
\hline 23 & CXCL12 & Chemokine (C-X-C motif) ligand 12 & - \\
\hline 24 & CXCL13 & Chemokine (C-X-C motif) ligand 13 & - \\
\hline 25 & CXCL16 & Chemokine (C-X-C motif) ligand 16 & - \\
\hline 26 & CX3CL1 & Chemokine (C-X3-C motif) ligand 1 & - \\
\hline 27 & GPI/AMF & Glucose-6-phosphate isomerase & - \\
\hline 28 & IFNA2 & Interferon, alpha 2 & - \\
\hline 29 & MIF & Macrophage migration inhibitory factor & - \\
\hline 30 & РPBP & Proplatelet basic protein (chemokine (C-X-C motif) ligand 7) & - \\
\hline 31 & SPP1 & Secreted phosphoprotein 1 & - \\
\hline 32 & \multicolumn{3}{|c|}{ Growth factors } \\
\hline 33 & BMP2 & Bone morphogenetic protein 2 & - \\
\hline 34 & BMP4 & Bone morphogenetic protein 4 & - \\
\hline 35 & BMP6 & Bone morphogenetic protein 6 & - \\
\hline 36 & BMP7 & Bone morphogenetic protein 7 & - \\
\hline 37 & CNTF & Ciliary neurotrophic factor & + \\
\hline 38 & CSF1 & Colony stimulating factor 1 (macrophage) & + \\
\hline 39 & CSF2 & Colony stimulating factor 2 (macrophage) & - \\
\hline 40 & CSF3 & Colony stimulating factor 3 (macrophage) & + \\
\hline 41 & LIF & Leukemia inhibitory factor (cholinergic differentiation factor) & - \\
\hline 42 & MSTN & Myostatin & + \\
\hline 43 & NODAL & Nodal growth differentiation factor & + \\
\hline 44 & OSM & Oncostatin M & - \\
\hline 45 & TGFB2 & Transforming growth factor, beta 2 & + \\
\hline 46 & THPO & Thrombopoietin & + \\
\hline \multirow[t]{2}{*}{47} & VEGFA & Vascular endothelial growth factor A & + \\
\hline & \multicolumn{3}{|c|}{ TNF superfamily } \\
\hline 48 & CD40LG & CD40 ligand & - \\
\hline 49 & FASLG & Fas ligand (TNF superfamily, member 6) & - \\
\hline 50 & LTA & Lymphotoxin alpha (TNF superfamily, member 1) & - \\
\hline 51 & LTB & Lymphotoxin beta (TNF superfamily, member 3) & - \\
\hline 52 & $\mathrm{TNF}$ & Tumor necrosis factor & - \\
\hline 53 & TNFRSF11B & Tumor necrosis factor receptor superfamily, member $11 \mathrm{~b}$ & - \\
\hline 54 & TNFSF10 & Tumor necrosis factor (ligand) superfamily, member 10 & - \\
\hline
\end{tabular}


Table I. Continued

\begin{tabular}{|c|c|c|c|}
\hline Number & Symbol & Description & Detectable \\
\hline 55 & TNFSF11 & Tumor necrosis factor (ligand) superfamily, member 11 & - \\
\hline 56 & TNFSF13B & $\begin{array}{c}\text { Tumor necrosis factor (ligand) superfamily, member 13b } \\
\text { Interleukins }\end{array}$ & - \\
\hline 57 & IL1A & Interleukin 1, alpha & + \\
\hline 58 & IL1B & Interleukin 1 , beta & + \\
\hline 59 & IL1RN & Interleukin 1 receptor antagonist & - \\
\hline 60 & IL2 & Interleukin 2 & - \\
\hline 61 & IL3 & Interleukin 3 (colony-stimulating factor, multiple) & - \\
\hline 62 & IL4 & Interleukin 4 & - \\
\hline 63 & IL5 & Interleukin 5 (colony-stimulating factor, eosinophil) & - \\
\hline 64 & IL6 & Interleukin 6 (interferon, beta 2) & - \\
\hline 65 & IL7 & Interleukin 7 & - \\
\hline 66 & IL8 & Interleukin 8 & - \\
\hline 67 & IL9 & Interleukin 9 & - \\
\hline 68 & IL10 & Interleukin 10 & - \\
\hline 69 & IL11 & Interleukin 11 & - \\
\hline 70 & IL12A & Interleukin $12 \mathrm{~A}$ & - \\
\hline 71 & IL12B & Interleukin 12B & - \\
\hline 72 & IL13 & Interleukin 13 & - \\
\hline 73 & IL15 & Interleukin 15 & - \\
\hline 74 & IL16 & Interleukin 16 & - \\
\hline 75 & IL17A & Interleukin 17A & - \\
\hline 76 & IL17F & Interleukin $17 \mathrm{~F}$ & - \\
\hline 77 & IL18 & Interleukin 18 (interferon-gamma-inducing factor) & + \\
\hline 78 & IL21 & Interleukin 21 & - \\
\hline 79 & IL23A & Interleukin 23 , alpha subunit p19 & + \\
\hline 80 & IL22 & Interleukin 22 & + \\
\hline 81 & IL24 & Interleukin 24 & - \\
\hline 82 & IL27 & Interleukin 27 & - \\
\hline & & Cytokines & \\
\hline 83 & ADIPOQ & Adiponectin, C1Q and collagen domain containing & - \\
\hline 84 & IFNG & Interferon, gamma & - \\
\hline
\end{tabular}

functionality and subsequently led to the induction of apoptosis $(19,20)$.

Furthermore, indirect effects can also be assumed, which regulate adjacent cells via the secretion of soluble factors and result in an amplification of the CAP effect. Treatment with CAP has been shown to alter the expression of several thousand genes and may affect important factors such as growth factors, cytokines, interleukins, and members of the tumor necrosis factor (TNF) superfamily. As a result, important cell responses such as proliferation, inflammation, and immune response can be modulated in cancer cells as well as adjacent non-malignant cells $(21,22)$.

The aim of this study was to investigate changes in cytokine and chemokine expression in OS cells treated with CAP. The pattern of these factors would significantly influence the behavior of both tumor cells as well as cells of the tumor microenvironment. This would be of particular interest with regard to the biological effect of CAP, especially in therapy approaches where CAP is applied to OS patients.

\section{Materials and Methods}

Cell culture. The human OS cell lines U2-OS and MNNG/HOS (purchased from the American Type Culture Collection, Manassas, VA, USA) were propagated in Dulbecco's modified Eagle's medium (DMEM) containing $1.0 \mathrm{~g} / \mathrm{l}$ glucose supplemented with $10 \%$ foetal bovine serum, $1 \mathrm{mM}$ sodium pyruvate, and $1 \%$ penicillin/ streptomycin (all PAN Biotech, Aidenbach, Germany) in a humidified atmosphere at $5 \% \mathrm{CO}_{2}$ and $37^{\circ} \mathrm{C}$. A total of $4 \times 10^{6}$ cells were seeded on an uncoated cell culture plate. After 4 days, cells were washed twice in phosphate-buffered saline (PBS) and detached using $0.1 \%$ trypsin $/ 0.04 \%$ ethylendiaminetetra-acetic acid (EDTA) and resuspended in DMEM.

CAP treatment. The atmospheric plasma jet kINPen MED (Neoplas Tools, Greifswald, Germany) was utilized for CAP generation (carrier gas: argon, gas flow: $3 \mathrm{l} / \mathrm{min}$; supply voltage=65 V DC; frequency: $1.1 \mathrm{MHz}$ ). A total of $5 \times 10^{5}$ (U2-OS) and $5 \times 10^{5}$ (MNNG/HOS) cells were suspended in $500 \mu \mathrm{l}$ DMEM and treated for $10 \mathrm{~s}$ in suspension following a standard meandering pattern. After CAP treatment, cells were immediately transferred to poly-Llysine (PAN Biotech)-coated 24-well cell culture plates and 


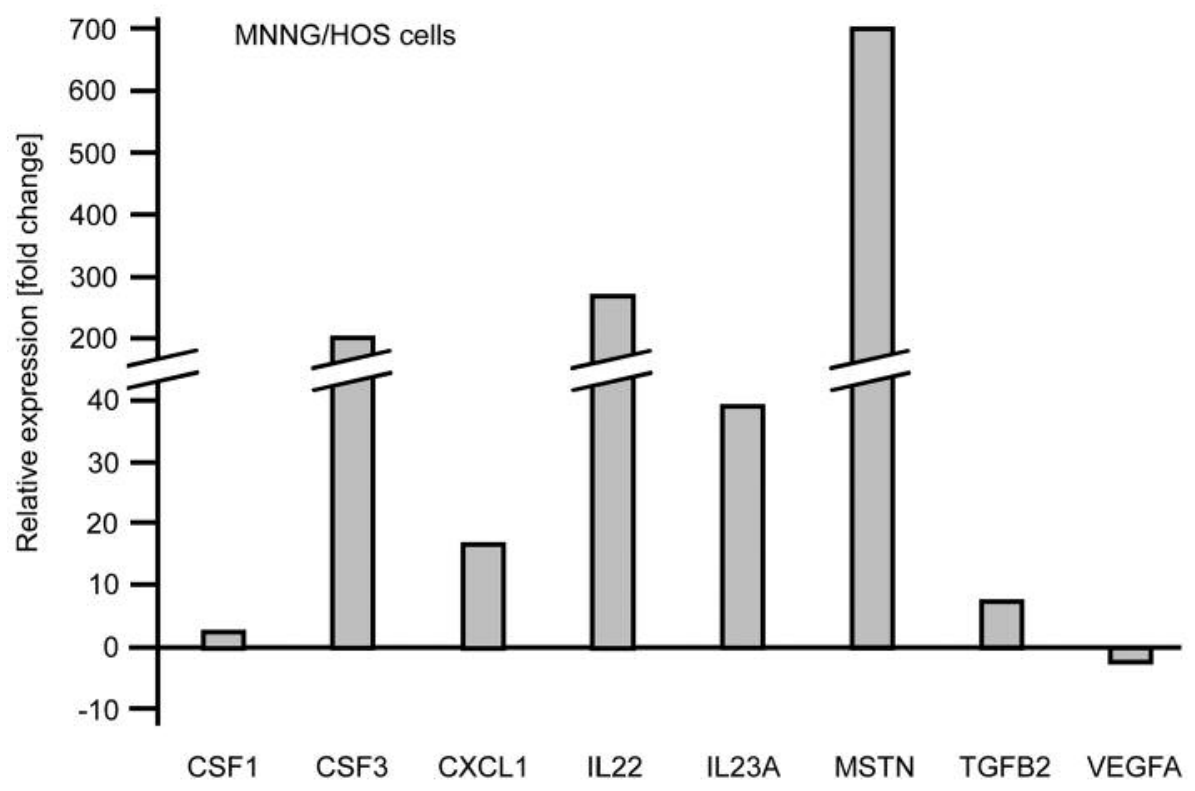

Figure 1. Relative expression of differentially expressed factors in CAP-treated MNNG/HOS cells. CAP-treated cells were administered to an RT ${ }^{2}$ Profiler PCR Arrays (Qiagen, Hilden, Germany) detecting 84 factors belonging to the groups of chemokines, growth factors, TNF superfamily members, interleukins, and cytokines.

incubated in DMEM with for $24 \mathrm{~h}$ (in a humidified atmosphere at $5 \% \mathrm{CO}_{2}$ and $\left.37^{\circ} \mathrm{C}\right)$.

Control group. A control group total of $5 \times 10^{5}$ (both U2-OS and MNNG/HOS) cells were suspended in $500 \mu \mathrm{l}$ DMEM and treated for $10 \mathrm{sec}$ only with Argon gas in suspension following a standard meandering pattern. After control treatment, cells were transferred and incubated similar to the CAP treated cells.

RNA preparation with peqGOLD TriFast ${ }^{T M}$. Cells were washed with $3.0 \mathrm{ml}$ PBS, harvested and total RNA was isolated with $500 \mu \mathrm{l}$ peqGOLD TriFast ${ }^{\mathrm{TM}}$ reagent (Peqlab Biotechnology, Erlangen, Germany) as described by the supplier. Isolated RNA was quantified spectrophotometrically with the NanoDropND-1000 (NanoDrop Technologies, Wilmington, DE, USA).

Quantitative real-time polymerase chain reaction-based array. $\mathrm{RT}^{2}$ Profiler PCR Arrays (Qiagen, Hilden, Germany) were used according to the supplier's instructions to monitor the expression of 84 genes of both OS cell lines for cytokine profiling (Table I). The ${ }^{\Delta} \Delta \mathrm{Ct}$ method was used to determine the relative quantity of gene expression. Microarray data was normalized against reference genes and CAP treated approaches were compared to control treated approaches by calculating the ${ }^{\Delta \Delta} \mathrm{Ct}$ for each gene of interest.

Statistics. For data evaluation, the graphics and statistics the Graph Pad Prism V5.01 software (GraphPad Software, La Jolla, CA, USA) was used. The values of two independent passages with both cell lines were averaged and displayed as fold expression. Due to this small number of runs, the standard deviation and the calculation of significance were omitted.

\section{Results}

The quantitative PCR-based analysis included a total of 84 factors belonging to the groups of chemokines, growth factors, TNF superfamily members, interleukins, and cytokines. For the analysis, a protein induction higher than the double $(\geq 2.0)$ and a reduction of expression to at least half $(\leq-2.0)$ were defined as cut-off values. Compared to control cells, 8 of these factors in MNNG/HOS cells (Figure 1) and 10 factors in U2-OS cells (Figure 2) were differentially regulated following CAP treatment.

In case of MNNG/HOS cells (Figure 1), 1 chemokine ((C$\mathrm{X}-\mathrm{C}$ motif) ligand 1 (CXCL1; 16.8-fold)), 2 interleukins (interleukin-22 (IL-22; 267.5-fold) and interleukin 23 submit alpha (IL23A; 38.9-fold)), and 4 growth factors (colony stimulating factor 1 (CSF1; 2.5-fold), colony stimulating factor 3 (CSF3; 202.5-fold), myostatin (MSTN; 700.0-fold), and transforming growth factor $\beta 2$ (TGF $\beta 2 ; 7.3$-fold)) were induced by CAP treatment. Only the expression of a single factor (vascular endothelial growth factor-A (VEGFA; -2.7fold)) was attenuated after CAP treatment compared to control treated cells.

The treatment of U2-OS cells with CAP (Figure 2) led to the induction of 3 chemokines (complement component 5 (C5; 3.2-fold), chemokine (C-C motif) ligand 5 (CCL5; 2.3 fold), and chemokine (C-X-C motif) ligand 1 (CXCL1; 2.6fold)), 4 interleukins (interleukin 1 alpha (IL-1A; 6.0-fold), 


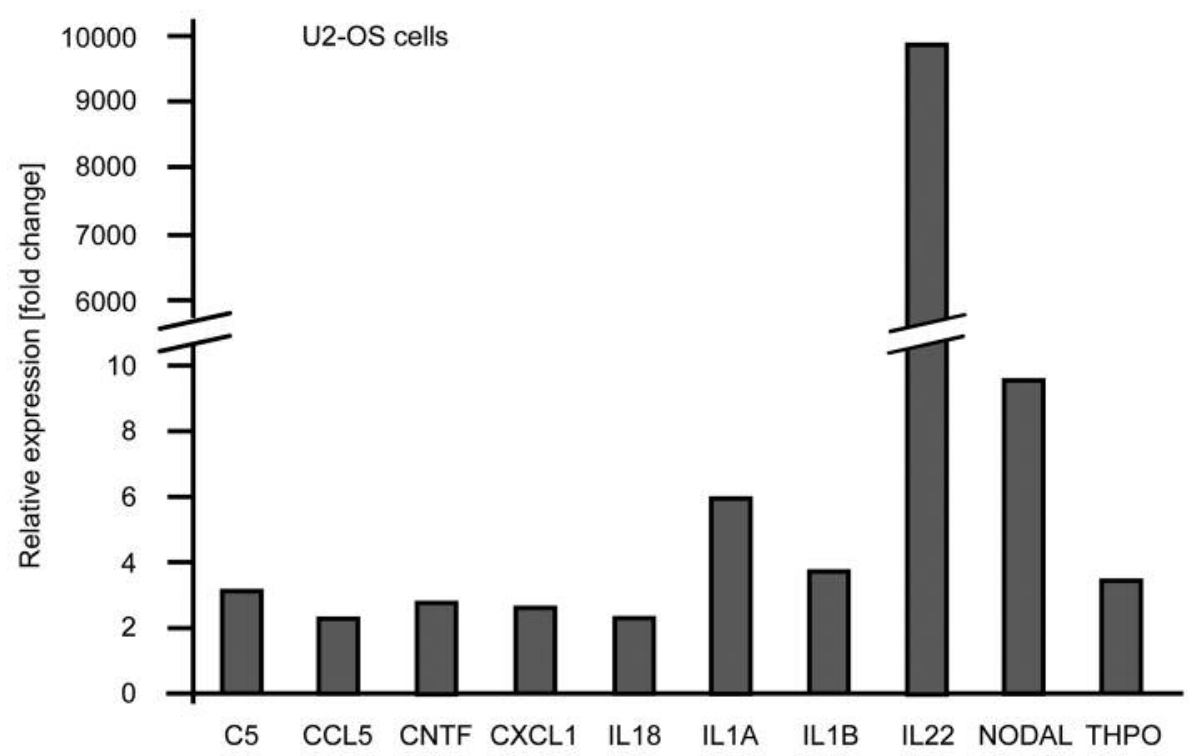

Figure 2. Relative expression of differentially expressed factors in CAP-treated U2-OS cells. CAP-treated cells were administered to an RT2 Profiler PCR Arrays (Qiagen) detecting 84 factors belonging to the groups of chemokines, growth factors, TNF superfamily members, interleukins, and cytokines.

interleukin 1 beta (IL-1B; 3.9-fold), interleukin-18 (IL-18; 2.3 -fold), and interleukin-22 (IL-22; 98,430.9-fold)), and 3 growth factors (ciliary neurotrophic factor (CNTF; 2.8 -fold), Nodal growth differentiation factor (NODAL; 9.5 -fold), and thrombopoietin (THPO; 3.5-fold)).

\section{Discussion}

This study showed, for the first time, the modulation of gene expression after CAP treatment in OS cells. The research focused on cellular factors which, as secretory factors, regulate proliferative, immunological, and inflammatory processes in the microenvironment of tumors. However, the analyses were limited to the expression rate of the factors on the mRNA level. The further processing and in particular the secretion of the molecules into the extracellular space were not considered. In this respect, this is an important limitation of this study.

In the two OS cell lines used, 8 (MNNG/HOS cells) and 10 (U2-OS cells) factors were differentially expressed. Two of these factors were identified as CAP modulated in both cell lines. These were chemokine CXCL1 and interleukin IL-22, which were significantly upregulated in both OS cell lines by CAP treatment. While the induction of the CXCL1 expression by 16.8 -fold (MNNG/HOS cells) and 2.6-fold (U2-OS cells) was comparatively moderate, IL-22 was increased by several hundred to several thousand times in both OS lines (MMNG/HOS: 267.5-fold; U2-OS: 98,430.9fold). CXCL1 as well as IL-22 possess pro-oncogenic properties in the tumor biological context. CXCL1 controls cell growth, epithelial-stroma interactions, and cell motility and has been described as a negative prognostic biomarker in some tumor entities including skin, colon, and prostate cancer (23-25). In OS cells, expression of chemokines has been generally defined as biomarker of tumor progression (26). The tumor biological function of IL-22 is similar. It correlates with tumor progression in gastric, colorectal, and pancreatic cancer $(25,27,28)$ and determines the epithelial-to-mesenchymal transformation of breast cancer cells (29). For both factors, CXCL1 and IL-22, no data on their role in the development of OS are, so far, available. However, this study suggests that they may have prooncogenic properties.

The remaining 14 factors differentially expressed after CAP treatment could only be detected in one of the two OS cell lines. This is presumably due to the high individuality of each tumor, which occurs frequently in the clinical situation. Such differences on the molecular and cellular level could also explain the individual response and the individual progress of OS. If examined in tumor cells, prooncogenic functions can also be attributed to these 14 factors. CSF-1, CSF-3, and NODAL for example, have been associated with progression in breast, and prostate cancer $(30,31)$. The four groups of chemokines (CXC, CC, CX3C, and $\mathrm{C}$ chemokine ligands) play central roles in tumorigenesis, including angiogenesis, and are therefore also discussed as targets for anticancer therapies (32). Growth factors are also involved in growth and progression in many tumor types (33). However, growth factors of the TGF $\beta$ 
family play a special role here, since they can have both prooncogenic and tumor suppressive functions. These depend on the tumor stage and play an important role in therapy resistance, for example (34). Consequently, the tumor biological role of CAP-induced TGF 32 in MNNG/HOS cells cannot be determined beyond doubt.

VEGFA was the only factor whose expression rate was reduced by CAP treatment of MNNG/HOS cells. The VEGF pathway is one of the most important signalling cascades in angiogenic processes and is, therefore, both an important biomarker of tumor progression and a target for anticancer therapy (35). Thus, CAP-mediated repression of VEGFA expression would be an important tumor suppressive mechanism of CAP. This means that in addition to the antiproliferative effects shown in vitro and in vivo, CAP would also suppress blood supply to tumor cells, which is very important for clinical use in patients.

In summary, it can be said that the treatment of OS cells with CAP leads to induction of a number of growth-promoting and pro-oncogenic factors. This should probably to be understood as part of a stress response of cancer cells. However, in in vitro experiments with the cell lines used, CAP treatment led to significantly suppressed cell growth $(19,20)$, so that this effect may be negligible in a potential therapeutic application of CAP. On the other hand, CAP also leads to the induction of TGF $\beta 2$, a potentially tumor suppressive factor in OS, and to the suppression of the angiogenic factor VEGFA. Both could have pro-therapeutic effects in the application of CAP. This study also shows that only 16 of the 84 factors examined are modulated by CAP. There was no extensive systemic cell response with presumably far-reaching consequences for neighboring cells. Thus, it can be concluded that intraoperative treatment with CAP may represent a promising option for the future therapy of OS.

\section{Conflicts of Interest}

The Authors declare no conflicts of interest regarding this study.

\section{References}

1 Luetke A, Meyers PA, Lewis I and Juergens H: Osteosarcoma treatment - Where do we stand? A state of the art review. Cancer Treat Rev 40: 523-532, 2014.

2 Reiazi R, Akbari ME, Norozi A and Etedadialiabadi M: Application of cold atmospheric plasma (CAP) in cancer therapy: A review. Int J Cancer Manag 10: e8728, 2017.

3 Gümbel D, Bekeschus S, Gelbrich N, Napp M, Ekkernkamp A, Kramer A and Stope MB: Cold atmospheric plasma in the treatment of osteosarcoma. Int J Mol Sci 18, 2017.

4 Weltmann KD and Von Woedtke T: Plasma medicine - Current state of research and medical application. Plasma Phys Control Fusion 59: 014031, 2017.

5 von Woedtke T, Reuter S, Masur K and Weltmann KD: Plasmas for medicine. Phys Rep 530: 291-320, 2013.
6 Bekeschus S, Rödder K, Fregin B, Otto O, Lippert M, Weltmann KD, Wende K, Schmidt A and Gandhirajan RK: Toxicity and immunogenicity in murine melanoma following exposure to physical plasma-derived oxidants. Oxid Med Cell Longev 2017: 4396467, 2017.

7 Weiss M, Gümbel D, Hanschmann EM, Mandelkow R, Gelbrich N, Zimmermann U, Walther R, Ekkernkamp A, Sckell A, Kramer A, Burchardt M, Lillig $\mathrm{CH}$ and Stope MB: Cold atmospheric plasma treatment induces anti-proliferative effects in prostate cancer cells by redox and apoptotic signaling pathways. PLoS One 10(7): e0130350, 2015.

8 Tanaka H, Mizuno M, Ishikawa K, Nakamura K, Kajiyama H, Kano H, Kikkawa $\mathrm{F}$ and Hori M: Plasma-activated medium selectively kills glioblastoma brain tumor cells by downregulating a survival signaling molecule, AKT kinase. Plasma Med 1: 265-277, 2011.

9 Partecke LI, Evert K, Haugk J, Doering F, Normann L, Diedrich S, Weiss FU, Evert M, Huebner NO, Guenther C, Heidecke CD, Kramer A, Bussiahn R, Weltmann KD, Pati O, Bender C and von Bernstorff W: Tissue tolerable plasma (TTP) induces apoptosis in pancreatic cancer cells in vitro and in vivo. BMC Cancer 12: 473, 2012.

10 Kang SU, Cho JH, Chang JW, Shin YS, Kim KI, Park JK, Yang SS, Lee JS, Moon E, Lee K and Kim CH: Nonthermal plasma induces head and neck cancer cell death: The potential involvement of mitogen-activated protein kinase-dependent mitochondrial reactive oxygen species. Cell Death Dis 5(2): e1056, 2014.

11 Plewa JM, Yousfi M, Frongia C, Eichwald O, Ducommun B, Merbahi $\mathrm{N}$ and Lobjois V: Low-temperature plasma-induced antiproliferative effects on multi-cellular tumor spheroids. New J Phys 16: 043027, 2014.

12 Joh HM, Choi JY, Kim SJ, Chung TH and Kang TH: Effect of additive oxygen gas on cellular response of lung cancer cells induced by atmospheric pressure helium plasma jet. Sci Rep 4: 6638, 2014.

13 Bekeschus S, Wende K, Hefny MM, Rödder K, Jablonowski H, Schmidt A, Woedtke TV, Weltmann KD and Benedikt J: Oxygen atoms are critical in rendering THP-1 leukaemia cells susceptible to cold physical plasma-induced apoptosis. Sci Rep 7: 2791, 2017.

14 Hattori N, Yamada S, Tori K, Takeda S, Nakamura K, Tanaka H, Kajiyama H, Kanda M, Fujii T, Nakayama G, Sugimoto H, Koike M, Nomoto S, Fujiwara M, Mizuno M, Hori M and Kodera Y: Effectiveness of plasma treatment on pancreatic cancer cells. Int J Oncol 47(5): 1655-1662, 2015.

15 Daeschlein G, Scholz S, Lutze S, Arnold A, von Podewils S, Kiefer T, Tueting T, Hardt O, Haase H, Grisk O, Langner S, Ritter C, von Woedtke $\mathrm{T}$ and Jünger M: Comparison between cold plasma, electrochemotherapy and combined therapy in a melanoma mouse model. Exp Dermatol 22(9): 582-586, 2013.

16 Utsumi F, Kajiyama H, Nakamura K, Tanaka H, Mizuno M, Ishikawa K, Kondo H, Kano H, Hori M and Kikkawa F: Effect of indirect nonequilibrium atmospheric pressure plasma on antiproliferative activity against chronic chemo-resistant ovarian cancer cells in vitro and in vivo. PLoS One 8(12): e81576, 2013.

17 Mirpour S, Piroozmand S, Soleimani N, Jalali Faharani N, Ghomi H, Fotovat Eskandari H, Sharifi AM, Mirpour S, Eftekhari $\mathrm{M}$ and Nikkhah M: Utilizing the micron sized nonthermal atmospheric pressure plasma inside the animal body for the tumor treatment application. Sci Rep 6: 29048, 2016. 
18 Vandamme M, Robert E, Lerondel S, Sarron V, Ries D, Dozias S, Sobilo J, Gosset D, Kieda C, Legrain B, Pouvesle JM and Pape AL: ROS implication in a new antitumor strategy based on non-thermal plasma. Int J Cancer 130(9): 2185-2194, 2012.

19 Gümbel D, Gelbrich N, Weiss M, Napp M, Daeschlein G, Sckell A, Ender SA, Kramer A, Burchardt M, Ekkernkamp A and Stope MB: New treatment options for osteosarcoma-inactivation of osteosarcoma cells by cold atmospheric plasma. Anticancer Res 36(11): 5915-5922, 2016.

20 Gümbel D, Gelbrich N, Napp M, Daeschlein G, Kramer A, Sckell A, Burchardt M, Ekkernkamp A and Stope MB: Peroxiredoxin expression of human osteosarcoma cells is influenced by cold atmospheric plasma treatment. Anticancer Res 37(3): 1031-1038, 2017.

21 Arndt S, Landthaler M, Zimmermann JL, Unger P, Wacker E, Shimizu T, Li YF, Morfill GE, Bosserhoff AK and Karrer S: Effects of cold atmospheric plasma (CAP) on $\beta$-defensins, inflammatory cytokines, and apoptosis-related molecules in keratinocytes in vitro and in vivo. PLoS One 10: e0120041, 2015.

22 Bekeschus S, Schmidt A, Bethge L, Masur K, Von Woedtke T, Hasse $\mathrm{S}$ and Wende K: Redox stimulation of human THP-1 monocytes in response to cold physical plasma. Oxid Med Cell Longev 2016: 5910695, 2016.

23 Bandapalli OR, Ehrmann F, Ehemann V, Gaida M, MacherGoeppinger S, Wente M, Schirmacher P and Brand K: Downregulation of CXCL1 inhibits tumor growth in colorectal liver metastasis. Cytokine 57(1): 46-53, 2012.

24 Miyake M, Lawton A, Goodison S, Urquidi V and Rosser CJ: Chemokine (C-X-C motif) ligand 1 (CXCL1) protein expression is increased in high-grade prostate cancer. Pathol Res Pract 210(2): 74-78, 2014.

$25 \mathrm{Wu}$ T, Cui L, Liang Z, Liu C, Liu Y and Li J: Elevated serum IL-22 levels correlate with chemoresistant condition of colorectal cancer. Clin Immunol 147: 38-39, 2013.

26 Namløs HM, Kresse SH, Müller CR, Henriksen J, Holdhus R, Sæter G, Bruland OS, Bjerkehagen B, Steen VM and Myklebost $\mathrm{O}$ : Global gene expression profiling of human osteosarcomas reveals metastasis-associated chemokine pattern. Sarcoma 2012: 639038, 2012.
27 Wen Z, Liao Q, Zhao J, Hu Y, You L, Lu Z, Jia C, Wei Y and Zhao Y: High expression of interleukin-22 and its receptor predicts poor prognosis in pancreatic ductal adenocarcinoma. Ann Surg Oncol 21(1): 125-132, 2014.

28 Zhuang Y, Peng LS, Zhao YL, Shi Y, Mao XH, Guo G, Chen W, Liu XF, Zhang JY, Liu T, Luo P, Yu PW and Zou QM: Increased intratumoral IL-22-producing CD4+T cells and Th22 cells correlate with gastric cancer progression and predict poor patient survival. Cancer Immunol Immunother 61(11): 1965-1975, 2012.

29 Kim K, Kim G, Kim JY, Yun HJ, Lim SC and Choi HS: Interleukin-22 promotes epithelial cell transformation and breast tumorigenesis via MAP3K8 activation. Carcinogenesis 35(6): 1352-1361, 2014.

30 Kenney NJ, Adkins HB and Sanicola M: Nodal and cripto-1: Embryonic pattern formation genes involved in mammary gland development and tumorigenesis. J Mammary Gland Biol Neoplasia 9(2): 133-144, 2004.

31 Vallier L: Activin/Nodal and FGF pathways cooperate to maintain pluripotency of human embryonic stem cells. J Cell Sci 118(19): 4495-4509, 2005.

32 Vandercappellen J, Van Damme J and Struyf S: The role of CXC chemokines and their receptors in cancer. Cancer Lett 267(2): 226-244, 2008.

33 Cross $M$ and Dexter TM: Growth factors in development, transformation, and tumorigenesis. Cell 64(2): 271-280, 1991.

34 Popp SL, Joffroy C, Stope MB, Buck MB, Fritz P and Knabbe $\mathrm{C}$ : Antiestrogens suppress effects of transforming growth factor$\beta$ in breast cancer cells via the signaling axis estrogen receptor$\alpha$ and Y-box Binding Protein-1. Anticancer Res 33(6): 24732480, 2013.

35 Lee SH, Jeong D, Han YS and Baek MJ: Pivotal role of vascular endothelial growth factor pathway in tumor angiogenesis. Ann Surg Treat Res 89(1): 1-8, 2015.

Received November 10, 2018

Revised November 23, 2018

Accepted November 26, 2018 